\title{
L'ANARCHIE MONÉTAIRE ET SES REMÈDES \\ CHEZ LES ANCIENS GRECS
}

PAR

M. THÉODORE REINACH

MEMBRE DE LINSTITUT

EXTRAIT

DES MÉMOIRES DE L'ACADÉMIE DES INSCRIPTIONS ET BELLES-LETTRES

TOME XXXVIII, $2^{2}$ PARTIE

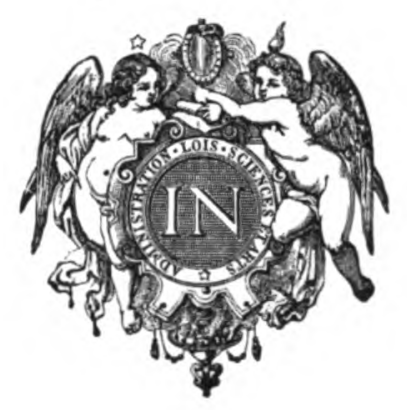

\section{PARIS}

\section{IMPRIMERIE NATIONALE}

LIBRAIRIE C. KLINCKSIECK, RUE DE LILLE, 11

$\operatorname{MDCCCCX} 1$ 